\title{
SLCE Future Directions Project: Sustaining a Dialogue, Challenging the Movement
}

\author{
Sarah Stanlick \\ Lehigh University
}

\author{
Edward Zlotkowski \\ Bentley University \& Puppet Showplace Theater
}

In 2015 - twenty years after the article "Does Service-Learning Have a Future?" in which Zlotkowski (1995) called attention to the importance of institutionalizing service-learning as an academic endeavor, complete with strong disciplinary connections, professional development and resources for faculty, and high pedagogical standards - the SLCE Future Directions Project (SLCEFDP) opened a broad conversation on the future of service-learning and community engagement (SLCE). Believing that earlier question to be largely settled at this point, the project poses new questions: "What are our visions now for the future of SLCE, why, and what will it take to get there?" and "How can we leverage the movement to advance those ends - intentionally, inclusively, and with integrity?" (Stanlick \& Clayton, 2015, p. 78).

From the beginning of the project, we have sought to honor and incorporate voices, experiences, and perspectives often marginalized in traditional academic writing. We have tried to bring together diverse perspectives and experiences, including in our project design an attempt to avoid academic jargon and an over-reliance on traditionally accepted (academic) knowledge centers. But we also readily acknowledge that we have a long way to go on this front: There are many voices yet to be heard. We seek to envision the future together as an inclusive, ever-expanding learning community that adopts a frame of bold vision, tangible action, and appreciative inquiry.

Functioning as an international learning community, the SLCE-FDP operates in three primary venues: an interactive website (www.slce-fdp.org); an ever expanding set of in-person conversations on campuses, in communities, and at conferences; and special sections of the Michigan Journal of Community Service Learning (MJCSL). Across all of these venues we invite colleagues to envision a bold future for the SLCE movement, and we are happy to report that the responses we have received over the past year have given us much food for thought on a broad range of ideas and viewpoints.

Our earliest contributors themselves brought a wide range of perspectives to the table: their own diverse personal and professional identities (undergraduate students, community leaders, social entrepreneur, and new as well as established faculty and staff members, to name just a few) and thought pieces that spanned many issues and settings. They grappled with the challenges and tensions of both local and global engagement, the identities held by all partners in SLCE (who variously self-define as practitioners, scholars, and practitioner-scholars), the dynamics of working within and outside of the academy, and issues of privilege and power. Priorities for the future of the SLCE movement articulated in that first set of thought pieces include, by way of example, the importance of asset-based course design in the first year (Bauer, Kniffin, \& Priest, 2015); students, community partners, and faculty seeing themselves as colleagues in SLCE who relate with one another and contribute to the work in non-hierarchical ways (Hicks, Seymour, \& Puppo, 2015); looking at institutional transformation through the lens of deep, pervasive, and integrated second order change (Saltmarsh, Janke, \& Clayton, 2015); and designing global service-learning with strong critical reflection and a focus on the challenges of re-entry into home communities (Pisco, 2015). The 2015 contributors have also used their thought pieces to advance their work in various ways: to gather contributors to a thematically similar edited volume, in professional development activities on their campuses, as a foundation for other writing, as a starting point for other collaborations with the same co-authors, and to share their thinking with colleagues, to name a few examples.

Since the publication of the first set of thought pieces in November of 2015, we have utilized several strategies to expand participation in the project. In addition to soliciting additional thought pieces, we have facilitated discussions at several conferences, hosted multi-partner dinner conversations, promoted interaction through our online learning community space, and collected input from many individuals and a few SLCE organizations on the idea of developing a national plan to guide the future evolution of SLCE - a strategy proposed in a 2015 essay by Howard and Stanlick. We have gath- 
ered ideas from colleagues across the United States - from Hawaii and Alaska through Iowa and Chicago to New England and the Appalachian Mountains - as well as abroad (e.g., Canada, Ireland, and Hong Kong). Ideas, questions, and feedback have been varied, critical, and constructive. The thread that runs through all of this work has been a deep commitment to nudging the SLCE movement and our world toward a better future. It is in this spirit that we present the Fall 2016 contributions to the SLCE Future Directions Project.

This special section shares thought pieces from 19 contributors, including the 4 lead project facilitators and the project's doctoral Fellow. This group also includes graduate students, volunteers with local and international community organizations, leaders of nonprofit organizations, campus administrators, new and veteran faculty members, consultants, and well-established SLCE scholars. They have produced six thought pieces that, in their own way and through their own lenses, respond to the following questions: What are our visions now for the future of SLCE? Why? What will it take to get there? In this set of thought pieces, contributors call the movement to ...

- Focus on empowerment of all stakeholders in community-university partnerships and break down narratives of heroic "helping" in order to move toward transformative reciprocity [Stanlick \& Sell]

- Listen to and learn from the ways community organizations navigate the tensions of enacting democratic engagement in a world that makes doing so difficult - specifically tensions around being asset-based, co-creative, placebased, and process-oriented [Whitney, Muse, Harrison, Edwards, \& Clayton]

- Create and value "front doors" into SLCErelated careers in the form of engaged graduate education - specifically, doctoral programs that transcend single disciplines and that incorporate SLCE practice and scholarship [Kniffin, Shaffer, \& Tolar]

- Reimagine assessment so that it walks the talk of the values of democratic engagement-

- specifically, explore and implement "values engaged assessment" as a counternormative way of framing assessment authentically [Bandy, Bartel, Clayton, Gale, Mack, Metzker, Nigro, Price, \& Stanlick]

- Critically reflect on such concepts as charity and justice in an age of neoliberal forces and address the difficulty and opportunity to advance justice-focused work in that environment [Blosser]
- Integrate into SLCE the lens of critical university studies (CUS) as a way to examine the motivations of universities in engaging in SLCE, to account for the social and economic privilege that spurs such engagement, and to cultivate among all partners awareness of the need for moral vigilance regarding the academy's commitments to engagement [Fine]

In addition to these thought pieces, this special section includes an essay by Kniffin and Howard that continues the discussion opened in a 2015 piece on the possibility of developing a national strategic plan for SLCE. Their essay shares responses to that proposal gathered over the past year through a survey of national SLCE organizations and through several discussions we have held at conferences and other venues as well as ideas for what such a plan might contain and how it might best be developed.

In the following paragraphs we explore three themes that emerge in our reading of the six thought pieces: the importance of holding tension, the influence of neoliberalism, and the disruption and distribution of power.

\section{Holding Tension}

Awareness of a variety of tensions emerges in this set of thought pieces; in that spirit, much of the thinking we see in them is framed more in terms of both/and rather than either/or. There seems to be a necessary and prevalent feature of SLCE that calls for navigating difficult waters and tangled expectations, motivations, and goals. Many of the contributors speak to a heightened sense of the moral, social, and political compromises practitioner-scholars may feel compelled to make in their SLCE work as a function of pressures related to institutionalization. With these challenges along every dimension of engaged work realized and illuminated, the authors get to the difficult work of trying to address and design for these tensions in productive and just ways.

In the thought piece by Whitney and colleagues, titled "Learning from and with Community Organizations to Navigate the Tensions of Democratic Engagement," stories from two community-based organizations highlight tensions between our commitments to democratic engagement and the internal and external norms and pressures that make living out those commitments difficult. The authors share some of the ways these organizations attempt to navigate these tensions. They also remind us that community engagement is happening in many instances without the involvement of higher education institutions and suggest not only that there is 
much to be learned from such examples but also that the presence of academic institutions in SLCE often further complicates matters and exacerbate tensions, especially when members of those institutions bring technocratic tendencies into partnerships with community organizations.

In "Critical University Studies, Globalization, and the Future of Service Learning," Fine turns a similar critical lens more directly on the academy. He prompts us to acknowledge the privilege and the sometimes problematic motivations that may underlie institutions' presumed commitments to engagement and urges us to incorporate critical reflection that explicitly examines institutions' agendas and the otherwise unquestioned assumptions about the meanings of service and partnership embedded in SLCE as a result of corporatizing and globalizing forces.

In "Beyond Superheroes and Sidekicks: Empowerment, Efficacy, and Education in Community Partnerships," Stanlick and Sell provide another look at tensions between cultural norms and the requirements of democratic partnerships. Having partnered for several years, they call our attention to the ways in which a variety of common incentives for example, the ways institutions and society often frame student leadership in hierarchical terms and the ways grant opportunities often encourage new programs and interventions over support processes already in place - can result in a "power dynamic that prizes [the] role of hero ... [while] relegate[ing] community partners to the role of sidekick, or worse, recipient." While narratives praising individual leadership, social entrepreneurship, and helping have gained much prominence, the authors remind us that partnership work requires humility, mutual empowerment, and co-creation.

The thought piece by Bandy and colleagues on "Values-Engaged Assessment: Reimagining Assessment through the Lens of Democratic Engagement" works with a similar tension. The authors explore the experience of being "torn between the democratic values [they] want to enact and often technocratic, neoliberal norms [they] feel pressured to accommodate in assessment." They encourage us not to shy away from this tension or be shut down by it but rather to embrace it and leverage it to critique and change underlying paradigms. Rather than thinking of assessment as a necessary evil to appease external entities and ensure financial support, they invite us to view it instead as an opportunity to more authentically live out our values. Nodding to tensions within tensions, this thought piece acknowledges that the values of democratic engagement on which what they refer to as "valuesengaged assessment" rests are themselves contest- ed and sometimes in tension with one another, not only with the dominant narratives of our society.

\section{Neoliberalism's Influence on Higher Education and SLCE}

Related to the first theme, holding tension, is the influence of neoliberal forces on higher education. As noted above, Bandy and colleagues point to "neoliberal norms" and the pressure to accommodate those expectations in the assessment of SLCE and the tension that causes when institutionally powerful forces have to be appeased within the assessment process. On the hopeful side, however, they write, "It is our conviction that the assessment work of SLCE practitioner-scholars can embody and nurture a set of relationships, practices, and modes of inquiry that is potentially transformative of technocratic and neoliberal tendencies in our institutions." In support of such a paradigm shift, they model and invite reimagining the values that underlie assessment - values such as rigor - through the lens of democratic engagement. The extent to which the authors of these thought pieces help us recognize the complexity of our work as SLCE practitioner-scholars in an age of pervasive neoliberalism is both critical and encouraging.

In "Resisting the Siren Song: Charting a Course for Justice," Blosser identifies the many ways in which we agree to practices and policies we know are insufficient, as a result of the reality of the many neoliberal forces exerted on our work from within and beyond the academy. As he says towards the end of his thought piece: "The hard part about justice work .... is that to do it we may have to push back against the stakeholders we have spent years cultivating . . . [who] we still need . . . if we are to exist within the higher education system." Indeed, he suggests that "the future of the movement will depend on the ability of SLCE leaders to recognize and navigate neoliberal incentives, using them to further our objectives but resisting the urge to let the work be co-opted."

Fine is equally clear about the influence of neoliberalism. He notes that "to look back on the past twenty years and forward to the next is to acknowledge higher education's rapid corporatization and internationalization" and expresses concern that "as higher education, deeply influenced by neoliberalism's pressures to marketize, adopts the structure and value systems of big business, it risks placing private interest before public concern." Powerfully arguing that SLCE "does not emerge in a vacuum" and that "resources are not innocent," Fine urges us to "engage with SLCE's ethical complications rather than assuming, in advance, that all SLCE efforts are 
inherently good." The reality of higher education's being implicated in neoliberalism requires that we look critically at, for example, such seemingly innocuous language as "global citizenship" and interrogate the market-driven commitments and assumptions that may otherwise remain hidden.

\section{Disruption and Distribution of Power}

Another theme we see recurring throughout the thought pieces as well as in the essay by Kniffin and Howard involves the disruption and distribution of power. Questions about who holds power to make decisions, generate scholarship, affect change, and create partnerships cut across contexts - whether within the academy or community organizations, local or national - and across roles - from nonprofit leader to faculty member to graduate student, to name a few examples.

Fine calls us to make the academy and its priorities a focus of critical analysis. The field of Critical University Studies (CUS), which he suggests SLCE learn from and use as a lens through which to examine our institutions, helps us see more clearly the ways in which higher education institutions enter into relationships with communities not as benign agents of assistance but as players with their own agendas. CUS "strategically implicates both individuals and communities in the moral muddle that is SLCE's relation to the global, corporate university," thus challenging traditional power structures and examining the motives of powerful and perhaps power-seeking institutions through the lenses of justice and ethics. "Teaching our partnerships" - reflecting critically on them in terms of whose agendas they serve, for example - can empower students to ask disruptive questions of their institutions.

Another approach to such power disruption can be found in the thought piece by Stanlick and Sell. The authors warn us of narratives that are created about and sometimes within community partnerships that can be disempowering and can reinforce hierarchical power dynamics that undermine the flourishing of communities and of the SLCE movement. Mechanisms must be put in place to ensure that all partners have a voice and that their voices are heard - a proposition that requires vulnerability and humility and can be threatening to academic institutions in which certitude and expertise have long been lionized. They offer as examples of such shared power co-creation of programming and research, reciprocal engagement on boards and relevant committees, and cultivating humility through critical reflection on the part of all stakeholders.

The thought piece by Whitney and colleagues explicitly shifts power to community voices in that it consists of stories from community organizations and calls for the SLCE movement to seek out, listen to, and learn from examples of democratic engagement that have no necessary connection to higher education. Given their candid sharing of the challenges they face in trying to be asset-oriented, co-creative, place-based, and process-focused as well as the details of how they navigate and even leverage the difficulties, we can learn much from these and other community organizations about "persistence and resilience in the face of the very norms we seek to disrupt and replace with more hopeful and empowering alternatives." Indeed, the authors suggest that such structures for decision-making, program development, communication, and power sharing can serve as models for democratic partnerships that do and do not include academic institutions.

In "Winding Pathways to Engagement: Creating a Front Door," Kniffin, Shaffer, and Tolar bring our attention to the need to empower graduate students - a traditionally underrepresented and, in some cases, marginalized population - to thrive in their identities as community-engaged practitionerscholars rather than to settle for limited opportunities patched together within traditionally siloed academic programs. Their call for the development of "front doors" - more explicit and formalized points of entry into SLCE-related careers - disrupts the power of the disciplines as the default home of scholars. In an academy without such "front doors," "students without a high level of persistence, the resources to devote significant time and attention to the search for a program, and/or strong connections in the field may never find appropriate pathways, with the consequence that the SLCE movement may lose their participation and leadership." Power translates into influence, and graduate students who have been invited into the SLCE movement and enabled to co-create knowledge with faculty and community colleagues and mentors as an integral part of their education will have the capacities to lead change as professionals and citizens, both within and beyond the academy. Power also translates into responsibility, and the authors therefore insist that "individuals already working in SLCE have a responsibility to make the invitation into this work compelling and clear - to institutionalize, formalize, and broaden pathways toward engagement."

\section{Conclusion}

The authors of this set of thought pieces remind us that, whether we like it or not, there will always be tensions as we wear our many hats, balance our many expectations, engage many voices, and envi- 
sion the future together. There is no such thing as an ideologically pure or politically neutral SLCE endeavor. Further, there is often a tendency to respond to social and conceptual challenges by polarizing phenomena and dismissing one set of alternatives, and we are pleased to see the authors of these thought pieces not only avoid doing that but in many ways model an alternative in their acknowledgements of complexities and tension points.

In addition, much of where we stand now rests on where we have been and what developments have brought us to the current moment: the transformation of higher education, the rapid pace of technology, and the geopolitical environment that produces the "wicked problems" with which we must grapple. However appealing it may seem, we cannot simply toss away our academic constraints unless we wish to return to the days of operating entirely as a form of volunteerism. We often see a related phenomenon in the tendency to bypass important contributions from years past instead of building on or adapting them. While we may have radically underestimated how difficult it would be to do engaged work with integrity from inside the academy, we should also be careful not to underestimate the value of the projects, programs, and partnerships we have helped create.

What is clear from the work of our colleagues in these thought pieces - whether within the academy or deeply entrenched in community organizations is that the winds of change are blowing. One need look no further than our current political climate institutionally, locally, nationally, and internationally - to see that we are a world at a pivot point. We are demanding more just, equitable, and inclusive forms of governance and representation; and regardless of political party or ideological leaning, the sociopolitical environment is one of increasing calls for agency, empowerment, and deep collaboration. This is a moment of opportunity for SLCE to be a movement and a mechanism to help nurture the development of engaged citizens who can help usher in democratic change. Through engaged scholarship and high-impact practices as well as responsible anchor-institution initiatives that challenge and shape our colleagues, our communities, and ourselves, we can model the way for our institutional and governmental structures and demand the type of fair and just treatment that our world needs now more than ever. SLCE provides a space for interactions among those voices and stakeholders to share perspectives, goals, and visions for a better world. What can we do in partnership and how do we get to that better world? Please enjoy the thought pieces sourced for this special section of the MJCSL and think about the ways in which you yourself might help nudge the movement and the world forward with your work.

\section{References}

Bauer, T., Kniffin, L. E., \& Priest, K. L. (2015). The future of service-learning and community engagement: Asset-based approaches and student learning in firstyear courses. Michigan Journal of Community Service Learning, 2(1), 89-92.

Hicks, T., Seymour, L., \& Puppo, A. (2015). Democratic relationships in service-learning: Moving beyond traditional faculty, student, and community partner roles. Michigan Journal of Community Service Learning, 2(1), 105-108.

Howard, J., \& Stanlick, S. (2015). A call for a national strategic plan. Michigan Journal of Community Service Learning, 22(1), 128-132.

Pisco, K. (2015). Deepening service abroad: A call for reciprocal partnerships and ongoing support. Michigan Journal of Community Service Learning, 2(1), 93-96.

Saltmarsh, J., Janke, E. M., \& Clayton, P. H. (2015). Transforming higher education through and for democratic civic engagement: A model for change. Michigan Journal of Community Service Learning, 2(1), 122-127.

Stanlick, S., \& Clayton, P. H. (2015). Introduction: Special section on the SLCE Future Directions Project. Michigan Journal of Community Service Learning, 22(1), 78-82.

Zlotkowski, E. (1995). Does service-learning have a future? Michigan Journal of Community Service Learning, 2(1), 123-133.

\section{Authors}

SARAH E. STANLICK (ses409@lehigh.edu) is the founding director of Lehigh University's Center for Community Engagement and a professor of practice in Sociology and Anthropology. She previously taught at Centenary University and was a researcher at Harvard's Kennedy School, assisting the U.S. Ambassador to the United Nations, Samantha Power. She has published in journals such as The Social Studies and the Journal of Global Citizenship and Equity Education. Her current interests include inquiry-based teaching and learning, global citizenship, transformative learning, and cultivating learner agency.

EDWARD ZLOTKOWSKI (ezlotkowski@bentley.edu) is professor emeritus of Literature and Media Studies at Bentley University. He is the founding director of the Bentley Service-Learning Center and has been a senior associate at the American Association for Higher Education, Campus Compact, and the New England Resource Center for Higher Education. He devotes much of his time to literacy initiatives and is a community partner with Puppet Showplace Theater in Brookline, Massachusetts. 